\title{
An Improved Multistage Variable-step MPPT Algorithm for Photovoltaic System
}

\author{
Ping Wang , Zhe Zhou, Mengmeng Cai , Jingbin Zhang \\ Key Laboratory of Smart Grid of Ministry of Education \\ Tianjin University \\ Tianjin, China \\ e-mail: garyzhou11@gmail.com
}

\begin{abstract}
This paper presents an improved multistage variable-step incremental conductance method to achieve the maximum power point tracking (MPPT). Compared with the traditional variable-step incremental conductance method, this improved algorithm optimizes the selection of the step size so that the tracking of the maximum power point is more quickly and the steady-state performance is better. Furthermore, the algorithm can still guarantee the quickness and accuracy of MPPT when the environmental conditions change suddenly and tremendously. At last, matlab simulation was applied to compare the characteristics of multistage variable-step algorithm with that of the other. And the simulation results verified that the improved algorithm has better dynamic and steady-state performance.
\end{abstract}

Keywords-photovoltaic system; MPPT; incremental conductance algorithm; boost circuit

\section{INTRODUCTION}

With the energy crisis and ecological problems becoming increasingly serious, solar energy, as a kind of inexhaustible clean energy, is getting more and more attention. However, as the cost of the photovoltaic power generation system is relatively high, and the highest conversion efficiency of the photovoltaic panels is merely around $20 \%^{[1]}$, the efficiency of PV inverter becomes crucial.

Considering the nonlinear characteristic of the PV panel, the realization of the maximum power point tracking (MPPT) can effectively improve the efficiency of the PV inverter. At present, the three most commonly used MPPT methods are constant voltage tracking method (CVT), perturbation and observation method $(\mathrm{P} \& \mathrm{O})$ and incremental conductance method (IncCond). Among them, CVT is easy to be achieved. However, as it neglects the influence of temperature and some other parameters on the output voltage of PV panel, the essence of CVT cannot be regarded as a real method of MPPT. P\&O is relatively simple in structure, but it can hardly guarantee both the quickness and accuracy of MPPT at the same time. Moreover, the direction of perturbation is constantly changing which would lead to a certain degree of energy loss. IncCond avoids the blindness of $P \& Q$ and it can guarantee the quickness of dynamic characteristics ${ }^{[2][3]}$. However, the traditional IncCond cannot guarantee both quickness and accuracy of MPPT at the same time in terms of the step size selection. Based on the IncCond, this article proposed an improved multistage variable-step incremental

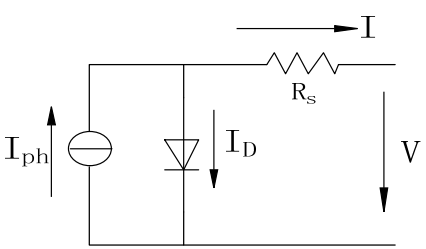

Figure 1. Equivalent circuit diagram of PV cell.

conductance method. Simulation results show that its dynamic and steady-state characteristics are good even when the environmental conditions change suddenly and tremendously.

\section{THE MATHEMATICAL MODEL AND CHARACTERISTICS} OF PHOTOVOLTAIC CELL

\section{A. The mathematical model of photovoltaic cel}

The principle of PV cell is based on photovoltaic effect of semiconductor materials. This effect means that semiconductor materials would absorb photon when exposed to light. Electron-hole pairs would be stimulated and their separation would generate electromotive force. According to this effect, when the PV cell is loaded with pure resistance, the equivalent circuit diagram is shown as Fig. $1^{[3]}$.

This article uses the versatile simulation model for PV cell proposed in [4]. The influence of ambient temperature, insolation level and parameters of the PV module are taken into consideration ${ }^{[4]}$. So it can precisely simulate the output characteristics of PV cell. Under the reference conditions (solar irradiance $S_{r}=1000 \mathrm{~W} / \mathrm{m}^{2}$, temperature of the PV cell $T_{r}=25^{\circ} \mathrm{C}$ ), assume the short-circuit current is $I_{s c}$, open-circuit voltage is $V_{o c}$, the voltage and current at the MPPT are $V_{m}$ and $I_{m}$. And the instantaneous voltage and current are $V$ and $I$ respectively. $R_{s}$ is serious resistance. $\mathrm{P}$ is the power of $\mathrm{PV}$ cell. $\alpha$ and $\beta$ are temperature coefficient of current and voltage under the reference solar irradiance. The characteristic equation is:

$$
I=I_{s c}\left(1-C_{1}\left(\exp \left(V / C_{2} V_{o c}\right)-1\right)\right)
$$

When the variations of solar irradiance and temperature are taken into consideration, (1) shall be:

$$
I=I_{s c}\left(1-C_{1}\left(\exp \left((V-D V) / C_{2} V_{o c}\right)-1\right)\right)+D I
$$

Where,

$$
\begin{gathered}
C_{1}=\left(1-I_{m} / I_{s c}\right) \exp \left(-V_{m} / C_{m} V_{o c}\right) \\
C_{2}=\left(V_{m} / V_{o c}-1\right) / \ln \left(1-I_{m} / I_{s c}\right)
\end{gathered}
$$




$$
\begin{gathered}
D I=\alpha \cdot\left(S / S_{r}\right) \cdot D T+\left(S / S_{r}-1\right) \cdot I_{S C} \\
D V=-\beta \cdot D T-R_{s} \cdot D I \\
D T=T-T_{r} \\
\alpha=0.0012 I_{s c} \\
\beta=0.005 V_{o c}
\end{gathered}
$$

\section{B. Output characteristic of $P V$ cell}

According to the mathematics model mentioned above and the parameters of TOP190(24) produced by a corporation in Tianjin, the Matlab simulation model is built. The parameters in detail can be seen in Tab.1.

The output characteristics through simulation are shown in Fig.2, Fig.3, Fig.4 and Fig.5. According to the P-V and I$\mathrm{V}$ curve, the output power of PV cell shows a strong nonlinear characteristic. As is shown in Fig.3, when the ambient temperature stays constant, the influence of the changes of the solar irradiance is great on short-circuit current, but little on open-circuit voltage. According to Fig.5, when the solar irradiance stays constant, open-circuit voltage would change with the ambient temperature, while the changes of short-circuit current is relatively slow.

\section{TABLE I. PARAMETERS OF PV CELL}

\begin{tabular}{|c|c|}
\hline Model number & TOP190(24) \\
\hline$V m$ & $36.7 \mathrm{~V}$ \\
\hline$I m$ & $5.20 \mathrm{~A}$ \\
\hline$V o c$ & $44.3 \mathrm{~V}$ \\
\hline$I s c$ & $5.70 \mathrm{~A}$ \\
\hline$R s$ & $1 \Omega$ \\
\hline$P$ & $190 \mathrm{~W}$ \\
\hline
\end{tabular}

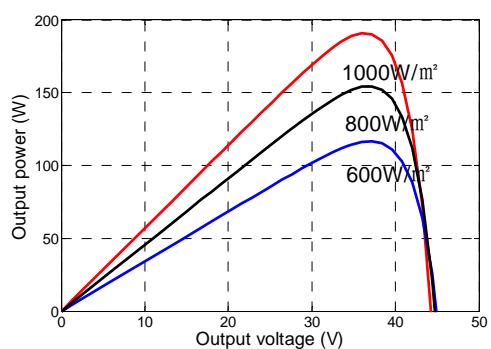

Figure 2. P-V characteristics of PV cell under different solar irradiance.

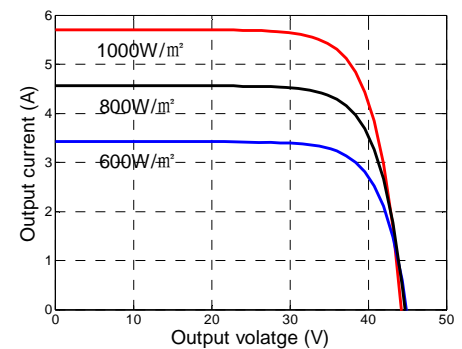

Figure 3. I-V characteristics of PV cell under different solar irradiance.

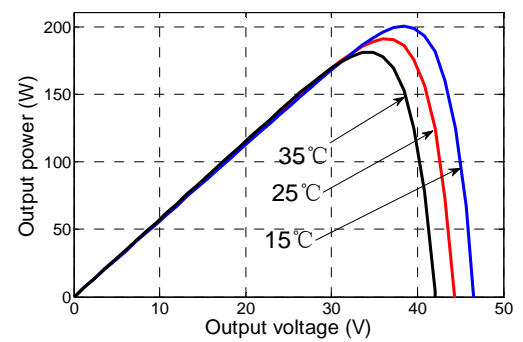

Figure 4. P-V characteristics of PV cell under different temperature.

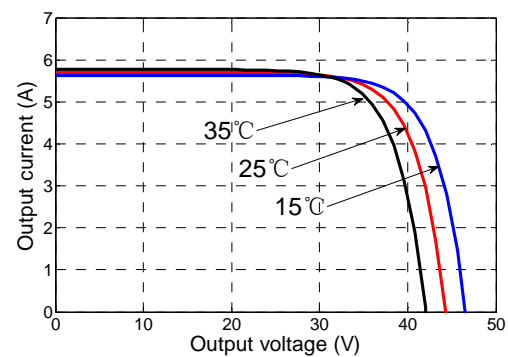

Figure 5. I-V characteristics of PV cell under different temperature.

\section{Multistage VARIABle-SteP MPPT MethoD}

According to the output characteristics of PV cell, under a specific cell temperature and solar irradiance, PV cell has an optimal operational point, which is called the maximum power point (MPP). According to Fig.2 and Fig.4, the maximum power point of PV cell would differ under different condition. Therefore, in order to improve the efficiency of photovoltaic generation system, it is necessary to achieve MPPT to make the PV cell work at the MPP constantly.

Incremental conductance method (IncCond) is one of the common ways to achieve MPPT. By comparing the dynamic conductance value $d I / d U$ and the negative number of static conductance value $-I / V$, the adjustment direction of the PV output voltage is determined. The blindness of $\mathrm{P} \& \mathrm{Q}$ is avoided and the relationship between operating point voltage and MPP voltage can be determined. $\mathrm{U}$ is the output voltage of PV cell and I is the output current ${ }^{[6]}$.

Reference [7] proposes an improved IncCond method based on the slope of power-voltage( $(\mathrm{P}-\mathrm{V})$ curve of photovoltaic cell. Though the variable-step control is achieved, the perfect performance cannot be reached since it neglects the asymmetry of P-V curve on both sides of the MPP. Reference [8] proposes a variable-step IncCond method to overcome the asymmetry of the P-V curve. The main principle can be described as follows. According to the V-I characteristics of PV cell, PV cell can be approximated as a constant current source when output voltage is relatively small; while when the voltage exceeds a marginal value and continues to increase, the output current would drop sharply so that it can be approximated as a constant voltage source. As a matter of fact, the range of constant current source region is four times the range of constant voltage source region. The operating voltage is less than the maximum 


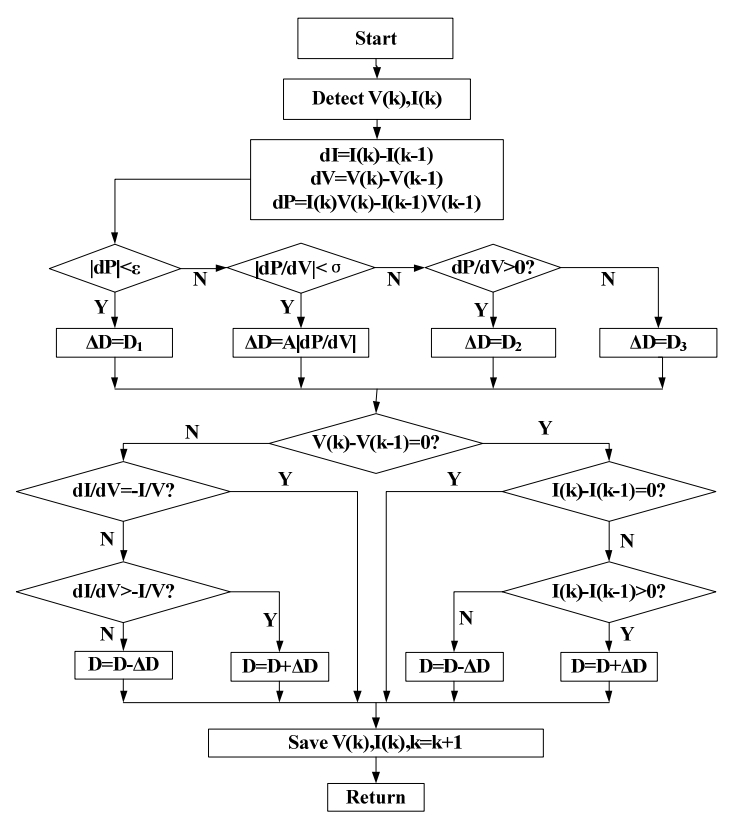

Figure 6. Flowchart of multistage variable-step MPPT.

power point voltage when the PV cell works in constant current region. So in this case, voltage is suitable to be increased by $4 \Delta V$ as the size of step. While if the PV cell works in constant voltage region, the operating voltage is greater than that of the maximum power point so that the output voltage should be decreased by $\Delta V$ as the size of step. However, when operating point closes to the maximum power point, the magnitude of the rate of power change tends to be equal rather than $1: 4$ on both sides of the MPP. Therefore, there are three disadvantages if the method is implemented to select step size. Firstly, even though the operating point can rapidly converge into the vicinity region around the MPP, the velocity to converge to the MPP itself would get slow. Secondly, the traditional variable-step IncCond method fails to guarantee both quickness and accuracy of MPPT at the same time, especially when the environmental conditions change suddenly. At last, the step size of traditional variable-step IncCond method is $|d P / d V|$ multiplied by a certain number. Its amplitude needs to be limited in case of system instability led by over-size step. If environment conditions change abruptly, there is no matching step big enough to follow that variation to achieve the MPPT quickly. Based on what mentioned above, this article proposes an improved multilevel variable-step MPPT algorithm. Its flowchart is shown in Fig.6.

As capacitor and inductance elements exist in the real circuit, when the operating point is close to the MPP, the influence of the ripple of voltage and current is great. Therefore, the duty ratio $\mathrm{D}$ is easily misjudged only by detecting voltage or current. To overcome this disadvantage, this article proposes a method to control the duty ratio by power detection. When $|d P|$ is less than $\varepsilon$, duty ratio $\mathrm{D}$ would be set equal to a small value $D_{l}$ which ensures the control accuracy and steady-state performance ${ }^{[9]}$. When $|d P / d V|$ is greater than the threshold $\sigma$, duty ratio $\mathrm{D}$ would be set equal to one of the two long-size steps $D_{2}$ and $D_{3}$ based on whether operating point is in the constant current region or voltage region. It ensures that system can make the voltage rapidly converge into the vicinity region around the MPP. For any other circumstance, $\mathrm{D}$ would be determined by the value of $A|d P / d V|$. In addition, the value of A cannot be set too big in case the environmental conditions change slightly.

\section{RESULT AND ANALYSIS OF SIMULATION}

\section{A. Establishment of MPPT system simulation model}

In two-stage photovoltaic system, MPPT control is achieved by a DC-DC converter which can match the PV cell output resistance and the input resistance of the converter ${ }^{[10]}$. Boost topology and buck topology are the most two common structures of DC-DC converter. According to the [11], boost topology has higher conversion efficiency than the buck topology so that this article establishes the MPPT simulation model based on boost circuit. The parameters of the PV cell in the simulation model are set according to those of TOP190(24). In addition, the load resistance shall not be set too small. Otherwise it may beyond the control ability of the boost circuit, which may eventually lead to the failure of the MPPT. Besides, the inductance in the boost circuit should not be set too small either in case of discontinuous inductive current. In the simulation model, the load resistance is $20 \Omega$, the inductance in boost circuit is $350 \mu \mathrm{H}$ and the capacitor in the load side is $100 \mu \mathrm{F}$. Considering the actual situation, sample frequency of power is $8 \mathrm{KHz}$, less than that of voltage and current. The details of the simulation model can be seen in Fig.7.

\section{B. Result and analysis of MPPT system simulation}

The temperature condition of the simulation is constant at $25^{\circ} \mathrm{C}$. Solar irradiance jumps from $0 \mathrm{~W} / \mathrm{m}^{2}$ to $600 \mathrm{~W} / \mathrm{m}^{2}$ at the beginning, $1000 \mathrm{~W} / \mathrm{m}^{2}$ at $0.06 \mathrm{~s}, 600 \mathrm{~W} / \mathrm{m}^{2}$ at $0.09 \mathrm{~s}$, and the simulation ends at $0.12 \mathrm{~s}$. System has been in steady state at $0.05 \mathrm{~s}$ so the analysis of system operation from 0 to $0.05 \mathrm{~s}$ can be omitted. The maximum output power under solar irradiance of $600 \mathrm{~W} / \mathrm{m}^{2}$ and $1000 \mathrm{~W} / \mathrm{m}^{2}$ can be known according to the simulation model of PV cell. So the maximum output energy of PV cell from $0.05 \mathrm{~s}$ to $0.12 \mathrm{~s}$ under ideal condition can be calculated. Comparing the ideal output energy with the actual output energy of PV cell with boost circuit in the simulation model, the efficiency of the input end of the MPPT photovoltaic system can be found.

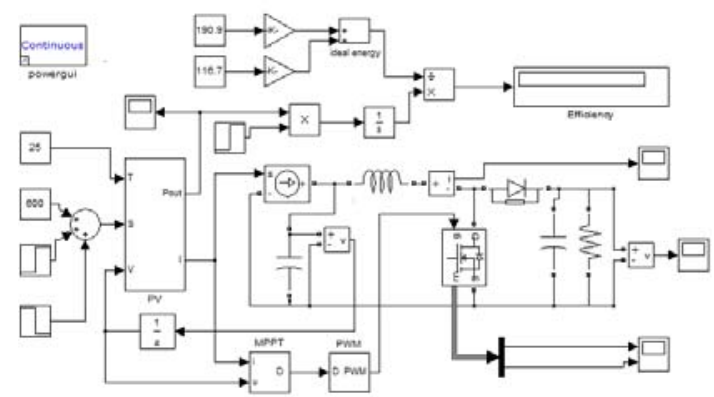

Figure 7. Simulation Model. 


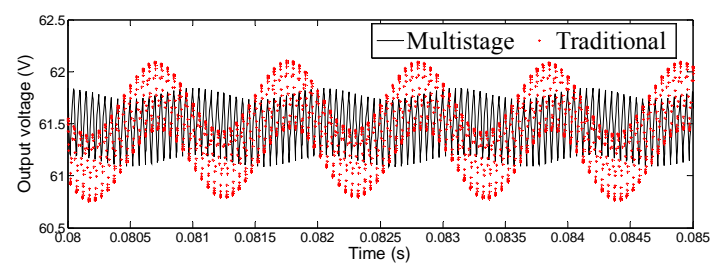

Figure 8. Waveform chart of output voltage.

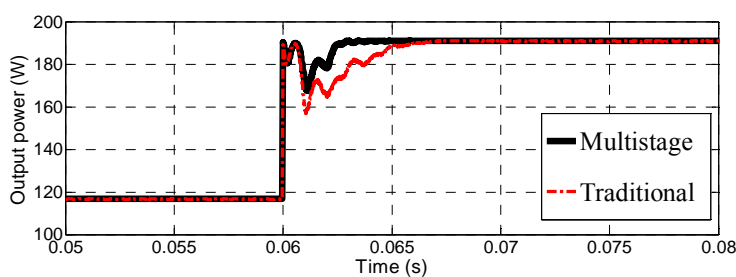

Figure 9. Curve of power when solar irradiance increase abruptly.

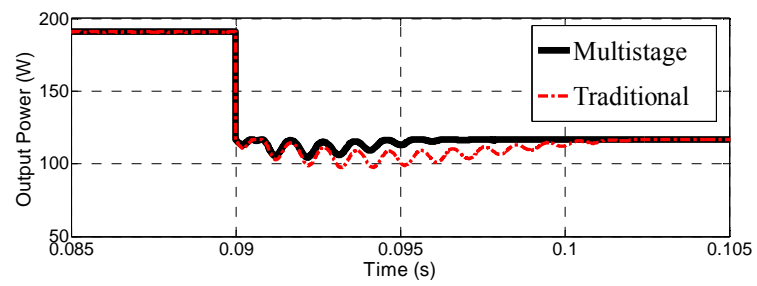

Figure 10. Curve of power when solar irradiance decrease abruptly.

When the multistage variable-step IncCond algorithm is implemented, set threshold $\varepsilon=0.5, \sigma=40$ and variable $A=5 \times 10^{-5}, D_{1}=2 \times 10^{-5}, D_{2}=0.03, D_{3}=0.02$, and $|d P / d V|$ shall be no less than 6 . Then the system efficiency is $99.58 \%$. When the traditional variable-step IncCond algorithm is implemented, step size is only determined by $A|d P / d V|$. A relatively perfect efficiency of $98.51 \%$, which is less than the former, is achieved through simulation. Under this circumstance, $A$ is $4 \times 10^{-5}$ and the amplitude of $|d P / d V|$ is limited from 3 to 500 .

Since the traditional variable-step IncCond lacks of the small step $D_{1}$ based on power detection, the value of A need to be smaller than that in multistage variable-step IncCond algorithm to ensure the tracking accuracy and steady-state performance. However, A cannot be set too small because of the required tracking speed. Therefore, the steady-state performance of multistage variable-step IncCond is better which coincides with the simulation results shown in Fig.8. The output voltage waveforms of these two algorithms under $1000 \mathrm{~W} / \mathrm{m}^{2}$ are compared in the chart. The waveform of the multistage variable-step IncCond method is of better steadystate performance. Its steady-state output voltage just oscillates within $0.8 \mathrm{~V}$.

If the ambient condition changes suddenly and tremendously, this improved algorithm shows great dynamic performance because it adopts two kinds of long step $D_{1}$ and $D_{2}$ according to whether the operating point is in constant current region or voltage region. As it is shown in Fig.9 and Fig.10, no matter the solar irradiance abruptly increase or decrease, faster MPPT is achieved compared to the traditional variable-step IncCond algorithm.

\section{CONCLUSION}

This article proposes an improved multistage variablestep IncCond MPPT algorithm. Verified by Matlab simulation, this algorithm is much better than the traditional variable-step one. Because of the optimization of step-size selection, it improves not only the steady-state performance but also the tracking quickness when conditions change dramatically. As a result, the efficiency of photovoltaic cell is improved.

\section{ACKNOWLEDGMENT}

This paper is supported by the Specialized Research Fund for the Doctoral Program of Higher Education of China (2012003211070).

\section{REFERENCES}

[1] Li R S, Zhou P Q, Li Y B. Terrestrial Photovoltaic Power Generation Systems and Applications. Beijing: China Electric Power Press, 2011, pp.20-33.

[2] Wu C F, Zhang J X, Chen Y K. Solar Photovoltaic Power Generation and Lighting System. Beijing: Science Press, 2009, pp.130-142.

[3] Li X Y, Wang X, Zhang F, Zhang Y. The MPPT Improved Algorithm and Simulation under Changing Irradiance of Grid-Connected PV Systems. Energy Technology, 2009, vol.5.

[4] Wang L Q, Sun X F. Photovoltaic Technology in Distributed Generation Systems. Beijing: Mechanical Industry Press, 2010, pp.63-71

[5] Fu J S, Xiao D S, Yang Q C. Analysis of characteristics of solar cells based on Matlab/simulink. Electronic Component Applications, 2012, vol.2, pp.44-46.

[6] Dong M, Yang J, Yu J R. Improved Maximum Power Point Tracking Experiment Method in Variable Environment. Proceedings of the Chinese Society of Universities for Electric Power System and Automation, 2012, vol.3, pp.41-45.

[7] Si C T, Zhou L, Zhang Y Y, Liu Q, Feng Y. Simulation Research on Output Characteristics of Photovoltaic Array and MPPT Control. East China Electric Power, 2010, vol.38(2), pp.284-287.

[8] Ma X J, Wu J Y, Li Y M, Zhang L H. The Research on the Algorithm of Maximum Power Point Tracking in Photovoltaic Array. 2009, vol.6, pp.36-38+51.

[9] Wang P, Ding H, Diao C Y. An Improved MPPT Algorithm Based on Traditional Incremental Conductance Method. PESA2011, Hong Kong, 2011, pp.1-4.

[10] Cheng J Z, Wu X K, Li S S, Zuo W X. Boost-based Two-level Gridconnected Photovoltaic Inverter System. High Voltage Engineering, 2009, vol.8, pp.2048-2052.

[11] Glasner, I. Advantage of boost vs. buck topology for maximum power point tracker in photovoltaic systems. $19^{\text {th }}$ Annu. IEEE Conv. Electr. Electron. Eng. Israel, Jerusalem, Israel, 1996, pp.355-358.

[12] Wang P, Ding H, The Design and Simulation Research on MPPT and Repetitive Control Strategy of Single-Phase Photovoltaic GridConnected System. Tianjin : Tianjin University, school of electrical engineering and automation, 2011. 